\title{
Desain Dan Kebijaksanaan Lingkungan
}

\author{
Lucky Hendrawan, Arleti M. Apin \\ Institut Teknologi Harapan Bangsa \\ lucky@ithb.ac.id
}

\begin{abstract}
Received: 13 August 2021; Revised: 02 October 2021; Accepted: 28 December 2021
DOI: http://dx.doi.org/10.37905/aksara.8.1.539-546.2022
\end{abstract}

\begin{abstract}
Abstrak
Jumlah papan iklan di daerah perkotaan begitu banyak memenuhi ruang publik .Terletak di persimpangan jalan, di pinggir jalan bahkan ditepi jalan bebas hambatan, hal ini membuat lingkungan menjadi riuh oleh visual. Beberapa di antaranya bahkan bertumpuk di satu titik secara bersamaan. Pemerintah kota telah membuat aturan baku untuk pemasangan papan iklan tentunya bagi kepentingan bersama. Pihak industri butuh pempromosikan produknya agar dikenal masyarakat. Sedangkan bidang desain berperan menjadi jembatan penghubung antara pihak industri dan masyarakat agar memperoleh informasi produk. Masing- masing pihak memiliki kepentingannya tanpa kompromi. Fenomena ini mengakibatkan timbulnya polusi visual di lingkungan ruang publik yang dipenuhi oleh informasi pada papan iklan. Penelitian ini dilakukan melalui metode kualitatif dengan pendekatan psikologis dan perilaku manusia. Harapan dari penelitian ini adalah mencari suatu jalan keluar yang perlu diambil agar masyarakat dapat merasa nyaman berada di lingkungan tempat berkegiatan.
\end{abstract}

Kata kunci : papan iklan, polusi visual,tanggung jawab moral

\begin{abstract}
The number of billboards in urban areas fills so many public spaces. Located at crossroads, on the side of the road and even on the edge of the freeway, this makes the environment visually chaotic. Some of them even stacked up at one point at the same spot. The government has made standard rules for the installation of billboards for the common common interest. The industry needs to promote its products to the public. Meanwhile, the design sector as a bridge between the industry and the public in order to obtain product information. Each party has its own interests without compromise. This phenomenon causes visual pollution in public spaces jammed with information on billboards. This research was conducted through a qualitative method with a psychological approach and human behavior. This research aim to find a way out that needs to make citizens feel comfortable in the environment where they have activities.

Keywords: billboards, visual pollution, moral responsibility
\end{abstract}

\section{Pendahuluan}

Setiap manusia berhak untuk menikmati keindahan lingkungan yang asri nyaman dipandang mata, baik di kawasan pegunungan, pantai, pedesaan, perkotaan, dan sebagainya. Segala yang terlihat indah sudah pasti akan mempengaruhi cara pandang manusia terhadap ruang kehidupannya. Secara prinsip dapat dikatakan bahwa sesungguhnya tidak ada satupun manusia yang menyukai polusi, kerusakan, kekumuhan. Kalaupun ada, hal tersebut diakibatkan oleh keterpaksaan akibat situasi dan kondisi. Hal 
ini tentunya berkaitan erat dengan sitem respon penginderaan manusia yang berdampak kepada kondisi cara berpikir, sikap mental, dan perilaku.

Contoh; bagi seseorang yang terpaksa hingga terbiasa hidup ditempat kotor akan cenderung terbiasa dengan kondisi kotor, sehingga ketika ia berada ditempat bersih baginya sampah kecil dianggap tidak bermasalah. Sebaliknya orang yang terbiasa hidup di tempat bersih akan terbiasa dengan kebersihan dan ia cenderung akan turut menjaga lingkungan itu.

Jadi ketika merujuk kepada pola kebiasaan hidup dalam rutinitas keseharian masyarakat kota besar soal riuhnya papan iklan boleh jadi tidak dianggap sebagai polusi visual, setidaknya akibat kejenuhan akhirnya mereka menjadi terbiasa oleh kondisi tersebut. Tetapi bagi kelompok pemerhati lingkungan keindahan kota dan para desainer yang masih memiliki tanggung jawab moral hal ini menjadi persoalan rumit dan serba salah sebab; mereka mengetahui dengan jelas ruang lingkup permasalahannya.

1. Desainer dan biro iklan (advertising), sudah pasti sangat mengharapkan adanya pekerjaan agar roda perusahaan dapat bergerak. Tentunya lebih banyak pekerjaan akan lebih baik karena keuntungan lebih banyak.

2. Kelompok industri sudah pasti membutuhkan sarana untuk memperkenalkan dan mempromosikan berbagai jenis produk atau jasa kepada masyarakat, maka cara efektif yang harus ditembuh adalah beriklan di pusat-pusat keramaian.

3. Pemerintah kota pun pemerintah daerah membutuhkan 'pemasukan' untuk kas daerahnya, maka mereka menyediakan perijinan serta lahan untuk pemasangan billboard beserta pajak dan biaya sewa lahan.

Melihat situasi, kondisi, serta faktor kepentingan tampaknya tiga kelompok ini tumbuh bersama saling terkait dan melengkapi. Namun demikian ada yang tidak boleh dilupakan yaitu persoalan lingkungan hidup keindahan ruang kota dan masyarakat yang berkegiatan di dalam wilayahnya.

Demi masing-masing kepentingan tiga kelompok tersebut di atas, boleh jadi mereka harus menutup mata dan berpura-pura tidak tahu tentang konsep lingkungan keindahan kota yang ideal. Artinya, mereka siap mengorbankan apapun demi tercapainya kepentingan masing-masing. Soal mengorbankan keindahan wajah kota dan ketidaknyamanan masyarakat itu lupakan saja. Mengorbankan keindahan wajah kota dan kondisi mental masyarakat di negeri ini toh sudah biasa, bukan hal baru yang perlu dianggap aneh.

Tarik menarik kepentingan seperti terurai di atas tentunya terjadi bukan tanpa sebab, hal ini terkait erat dengan persoalan "kesadaran dan kecerdasan" bangsa yang hidup dalam suatu negara. Hingga bagi mereka yang bergerak dalam ruang pendidikan khususnya perguruan tinggi selayaknya timbul suatu pertanyaan besar dan mendasar "Apa yang menyebabkan semua itu bisa terjadi?" karena mustahil ada akibat tanpa sebab yang melatar belakanginya. Untuk itulah penelitian dan kajian ini dilakukan.

Metode yang digunakan untuk mengupas persoalan ini adalah melalui deskriptif analitis dari sisi perilaku manusia dan efek psikologis, karena sangat berkaitan dengan fenomena kehidupan manusia dalam segala aktifitasnya. Data dihimpun dari sejumlah pengamatan secara langsung dan kepustakaan. Adapun tujuan dari penelitian ini adalah tanggungjawab apa yang dapat dilakukan dari lembaga pendidikan membentuk sikap para desainernya. 


\section{Hasil dan diskusi}

Desain komunikasi visual bidang periklanan secara khusus mengolah papan iklan yang dikenal dengan sebutan billboard yaitu media komunikasi visual berukuran besar yang dipasang di ruang publik. Pada umumnya billboard dipajang di tepi jalan besar atau bisa juga ditempatkan dalam posisi melintang jalan dengan memanfaatkan jembatan penyeberangan sehingga terlihat sangat mencolok.

Penempatan papan iklan diberbagai lokasi dengan posisi tertentu diperhitungkan sedemikian rupa agar tidak luput dari perhatian masyarakat terutama bagi pemirsa yang menjadi sasarannya, dalam bidang desain komunikasi visual hal tersebut masuk dalam perencanaan strategi media komunikasi. Soal nanti pada gilirannya papan iklan ukuran besar itu akan menjadi sampah visual yang mengganggu keindahan lingkungan boleh jadi terabaikan atau memang sengaja tidak dipedulikan.

Desain komunikasi visual khususnya yang bergerak dalam bidang periklanan adalah salah satu cabang ilmu yang mengolah pesan secara visual dan tekstual untuk massa. Perilaku manusia dan desain perlu diukur untuk diselaraskan dengan ruang public dan penggunanya (Bay Brix Nielsen et al., 2021). Jadi salah satu media yang sering digunakan adalah papan iklan berukuran besar dan diletakkan di tempat strategis hingga mudah dibaca.

Dilain pihak perkembangan teknologi cetak digital rupanya turut ambil bagian dalam melancarkan pembuatan berbagai jenis dan ukuran papan iklan. Alat berteknologi digital yang mempermudah proses teknis banyak membuka peluang usaha (Ferdy \& Sari, 2020). Selain lebih cepat, murah juga mudah maka tidak aneh jika papan iklan semakin banyak dijumpai pada ruang publik baik in-door maupun out-door.

Dapat dipastikan bahwa secara umum lingkungan kota besar terutama pada titik strategis akan menjadi sasaran bagi para pengiklan, masuk dalam program perencanaan strategisnya biro iklan. Tentu hal tersebut dilakukan karena kota besar merupakan ruang keramaian kegiatan masyarakat serta pusat pergerakan roda ekonomi maka dapat dianggap sebagai lokasi komunikasi yang sangat tepatnya menguntungkan. Posisi dan penempatan papan iklan ada yang tak sesuai dengan aturan pada Keputusan Walikota Semarang...(Dyah et al., 2017).

Tetapi inti masalahnya bukan itu. Berapa banyak masyarakat peduli dengan pesan yang terdapat pada ratusan papan iklan di tepi jalan dan yang melintang jalan? Berapa banyak pesan yang terserap dan mengendap dalam ingatan publik? Hal penting yang tidak boleh dilupakan ialah prinsip iklan yaitu menanamkan suatu pesan selama mungkin dalam ruang ingatan masyarakat. Secara alami tampilan yang diterima penglihatan direspon syaraf dan menimbulkan suatu ungkapan kreatif, hal ini penting untuk dipahami (King, 2018).

Kelompok industri yang bergerak dalam bidang produk dan jasa dapat dikatakan sebagai sumber penggerak roda perekonomian suatu negara. Maka sudah tentu pihak pemerintah memberikan dukungan penuh kepada kelompok masyarakat industri, walau dibalik itu tidak sedikit rongrongan yang memberatkan kinerja para pengusaha. Tapi di Indonesia hal itu terpaksa harus dimaklumi, pepatah "gugur satu tumbuh seribu" mungkin berlaku juga dalam dunia industri.

Dalam dunia industri dikenal istilah "perang bintang" yang artinya melakukan serangan melalui berbagai media komunikasi baik cetak maupun elektronik, dan lain 
sebagainya. Banyak perbincangan tentang kondisi kehadiran yang mampu menghasilkan pemikiran baru dalam dunia usaha (Homayoun \& Henriksen, 2018). Ada tiga tujuan yang harus mereka dapatkan dari perang bintang tersebut yaitu; 1). Merk dagang dalam bentuk brand harus dikenal masyarakat. 2). Merk dagang harus berada pada posisi teratas dalam ingatan masyarakat. 3). Merk dagang harus tampil meyakinkan dan dapat dipercaya.

Oleh sebab itu puluhan bahkan ratusan papan iklan jenis industri produk dan jasa harus berjuang keras untuk merebut perhatian masyarakat. Tentunya tidak cukup hanya dipasang satu billboard di satu lokasi saja. Secara strategi mereka harus membuat 'jebakan mata' diberbagai lokasi yang dianggap strategis. Maka masyarakat industri membutuhkan bantuan dari divisi periklanan yang dianggap ahli dalam menanamkan merk dagang serta pesan keunggulan produk atau jasa.

Dapat dipastikan fenomena perang bintang melalui media komunikasi di ruang publik itu menjadi anugerah bagi biro periklanan dan bagian prduksi, serta tidak ketinggalan hal ini pun menjadi musim panen bagi beberapa dinas pemerintahan yang bergerak dibidang papan reklame.

Pemerintah kota dan pemerintah daerah sebetulnya sudah mengetahui tentang adanya undang-undang yang mengatur pemasangan media iklan berskala besar. Mereka juga yang seharusnya mengawasi, menjaga, serta menjalankan peraturan tersebut secara konsisten.

Sekarang ini dapat dilihat peningkatan jumlah papan iklan di ruang publik makin bertambah banyak. Mulai dari tepian jalan hingga daerah pemukiman. Sering pula ditemui penumpukkan billboard dari jenis perusahaan yang berbeda-beda berebut tempat dan perhatian publik. Utamanya di daerah perkotaan pada tempat-tempat keramaian, maka sejumlah papan besar berjajar saling berdesakan disatu titik.

Tidak dapat disangkal pada faktanya persoalan papan iklan ini menjadi lahan perebutan kepentingan, antara membangun dan mempertahankan keindahan lingkungan kota dengan kepentingan kelompok industri. Walaupun jika ditelaah lebih jauh, selain yang berkepentingan sesungguhnya sangat sedikit masyarakat umum yang menyukai kehadiran papan iklan di ruang publik, apalagi dalam ukuran besar dan jumlah banyak.

Kawasan padat iklan dan papan nama perusahaan selain tidak nyaman dipandang mata juga terasa 'mengotori' lingkungan. Namun demikian tampaknya hal tersebut belum mendapat perhatian khusus dari pihak pemerintah kota, uniknya justru keberadaan billboard dianggap menjadi sumber keuntungan banyak pihak.

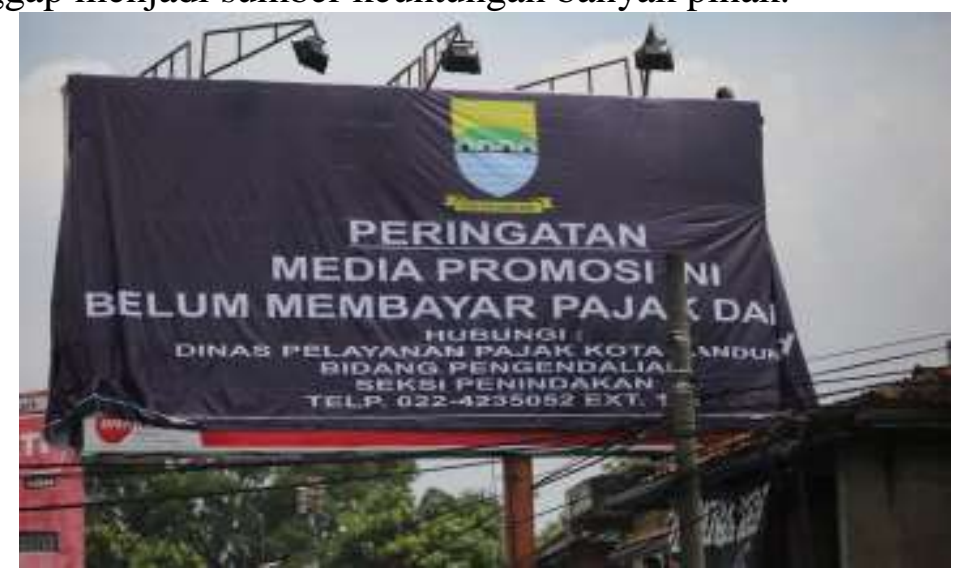

Gambar 1. Pajak papan iklan.

https://www.cermati.com/artikel/pajak-reklame-apa-itu-dan-bagaimana-perhitungannya 
Kegagalan pada karya desain berupa billboard sering terjadi karena seorang desainer terlalu fokus pada urusan estetika dan mengabaikan unsur strategi visual sehingga ketika karya berada di ruang publik kalah bersaing dalam merebut perhatian massa. Tentu kasus ini akan berbeda jika karya desain disebar-luaskan di daerah pinggiran, karya desain komunikasi visual dalam bentuk billborad hadir tanpa pesaing.

Tampaknya sudah menjadi konsekuensi logis jika kawasan pusat keramaian menjadi 'korban' sampah visual media komunikasi massa dalam berbagai bentuk; dari jenis poster, videotron, billboard, dll. tersebar mengepung masyarakat perkotaan. Lingkungan kota terutama pada kawasan ramai lintasan kendaraan serta aktifitas masyarakat akan riuh dengan media informasi baik berupa papan iklan maupun papan nama perusahaan.

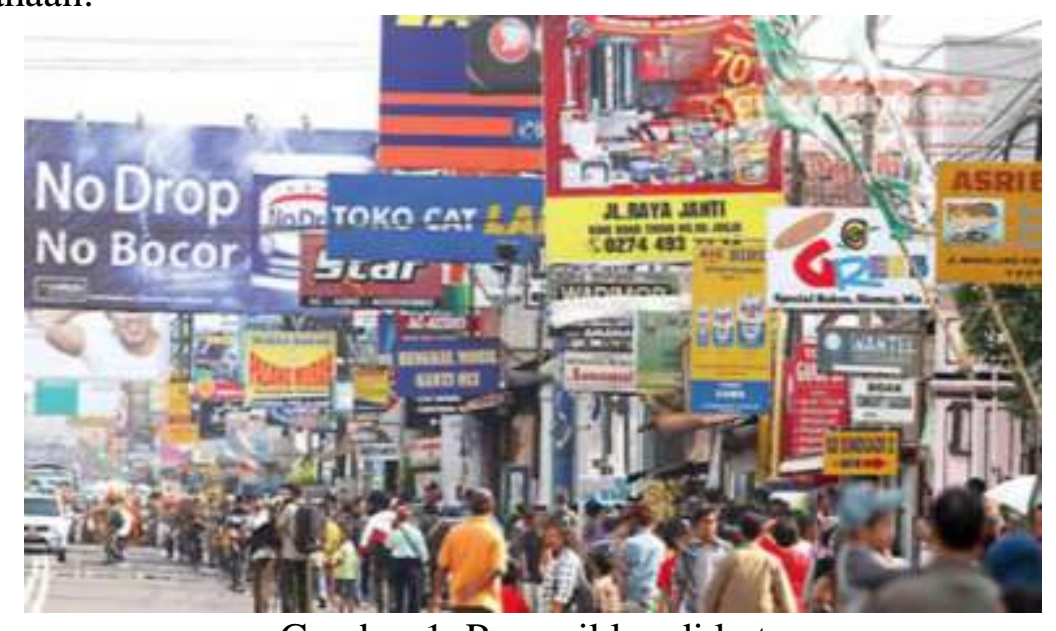

Gambar 1. Papan iklan di kota

Sumber: https://kompasnasional.com/papan-reklame-liar-bakal-ditumbangkan/

Khusus mengenai fenomena iklan di pusat kota sebagai pusat keramaian publik. Pusat kota memang bukan daerah hunian atau kawasan pemukiman. Secara umum pusat kota difungsikan sebagai lokasi perkantoran, kawasan transaksi perdagangan, pertokoan, tempat hiburan, dan sebagainya. Maka boleh jadi atas dasar pemikiran itulah wilayah perkotaan dijadikan arena perang bintang untuk segala merk dagang dalam bentuk papan reklame dengan berbagai jumlah dan ukuran, dan mereka tidak mengaggap bahwa itu adalah sampah visual yang mengganggu keindahan kota. Jika keriuhan visual iklan di perkotaan dianggap lumrah, mungkin perlu dibuat pepatah baru "kota tanpa papan iklan ibarat lautan tanpa garam".

Setelah lingkungan di pusat keramaian terlalu padat oleh papan iklan, sebagian kelompok industri bekerja sama dengan biro ikalan mengembangkan sayapnya ke kawasan pinggiran. Selain di tengah keramaian kota mereka mulai merambah daerah tertentu yang cukup padat dilintasi kendaraan. Mereka memasang papan iklan secara repetitif dalam jarak tertentu.

Dampak dari kepungan media komunikasi periklanan yang tersebar di kota dan di daerah tentu tidak boleh diabaikan. Masyarakat dari berbagai kelas ekonomi, pendidikan, umur, gender, dan seterusnya dipaksa untuk melihat, merekam, dan mengingat merek dagang tertentu. Bagi mereka puluhan merk dagang itu entah dibutuhkan entah tidak, yang jelas pesan telah masuk dalam rekaman dan mengendap sepanjang ingatan. 
Boleh jadi pesan-pesan iklan di tepi jalan yang terlewati sama sekali tidak dibutuhkan dan hanya menjadi sampah di dalam ruang ingatan mereka, lalu sebagiannya hanya menjadi impian dan angan-angan yang ingin didapatkan kelak pada saat mereka mampu membelinya (perubahan cara berpikir dan mentalitas).

Kondisi sosial di Indonesia sangat heterogen dari segala aspek, dan hal ini tentu amat pelik dalam suatu pencarian solusi. Tingkat pendidikan, taraf ekonomi, status social yang beragam merupakan situasi nyata, tak bisa dilakukan pengambilan keputusan secara gegabah karena bisa menimbulkan dampak yang tak terduga dan tak diinginkan. Perilaku secara umum seringkali tak memperhitungkan situasi ini, menimbulkan perilaku diluar rencana. Saat pemirsa menerima pesan dari papan iklan, maka akan tumbuh dorongan kuat untuk memperoleh produk tersebut (Sakti et al., 2020).

Perilaku yang dibentuk akibat menerima pesan dari papan iklan juga agak sulit dikendalikan, karena bersifat komunikasi terbuka sehingga sulit mencegah pemirsa yang bukan sasarannya. Hal ini sangat membuka dampak tak terduga, misalnya perilaku meniru atau mempraktekkan informasi dari iklan tertentu. Sejumlah siswa sekolah merokok dan ini adalah dampak dari melihat informasi produk dari papan iklan dari perusahaan (Herman Kurniawan, Adhar Arifuddin, 2017). Suatu bukti yang menunjukkan bahwa anak dibawah usia tertentu telah terpengaruh untuk merokok, oleh karena melihat informasi yang terpampang.

Pemandangan dan tatakota yang telah dirancang, seperti menjadi sia-sia dengan tampilan sejumlah papan iklan yang saling berebut tempat serta perhatian pemirsa. Keriuhan pemandangan ini menjadikan suasana terlihat kotor dan kurang tertata, antara taman kota, dan visual dari iklan saling silang membuat pemandangan kota kumuh dan acak.

Selain itu secara standar keindahan kota hal ini malah tak selaras dengan kebutuhan penghuni kota. Pemandangan yang riuh akan mempengaruhi mental seseorang. Setiap orang dapat melakukan keputusan untuk memperbaiki kondisi diri sendiri, terutama dalam mencapai taraf kesejahteraan mental. (Kearns \& Whitley, 2020). Kesibukkan perkotaan yang padat ditambah lagi dengan pemandangan yang simpang siur. Rambu lalu lintas, rambu penunjuk arah hingga pesan iklam yang tumpeng tindih. Hal ini amat tidak ideal bagi kenyamanan penghuninya. Emosi akan terganggu bukannya mendapatkan ketenangan. Sejumlah penelitian tentang hubungan keberhasilan akademik dan mutu kecerdasan berkaitan dalam dunia pekerjaan tak bisa dipisahkan dengan kondisi perasaan hati yang baik berpengaruh sekali terhadap keberhasilannya (Ratu et al., 2021).

Aturan pemerintah yang berkaitan dengan ruang public sebenarnya ada dan telah cukup baik, hanya saja dalam implementasinya di lapangan sering kali tidak dipatuhi. Banyak aturan yang dilanggar karena kepentingan tiap pihak, terutama dari pihak yang ingin memasang papan iklan di titik yang dianggap primadona. Akhirnya penumpukkan papan iklan secara acak berada dititik tersebut. Sebagai contoh peraturan daearah yang mengatur persoalan iklan di Daerah Khusus Ibukota Jakarta; Peraturan Daerah Nomer 12 Tahun 2011 tentang Pajak Reklame.

Lembaga pendidikan desain membentuk para sarjana untuk berkeja sebagai desainer professional. Memperkenalkan ilmu pengetahuan untuk mempengaruhi benak masyarakat, memasukkan informasi. Dalam tanggungjawab profesi, kita harus untuk menghasilkan sesuatu yang baru sekaligus baik dan sehat bagi lingkungan masyarakat luas (Burch, 2021). Logika bahwa penemuan dan kebaruan selalu diperlukan dalam 
desain,tetapi hal ini semua patut mempertimbangkan faktor keseimbangan lingkungan masyarakat luas dengan bijak (Nilsson \& Jahnke, 2018).

\section{Kesimpulan}

Melalui bahasan terurai di atas setidaknya dapat diambil dasar kesimpulan bahwa iklan yang sudah tersebar di ruang publik secara langsung menawarkan kebutuhan dan keinginan (need dan want) sehingga terbentuk pola berpikir konsumtif diberbagai golongan masyarakat. Tak mudah menguraikan pihak yang tekait sebab masing-masing pasti akan bertahan pada kepentingannya. Dari pihak tersebut, peluang untuk menjembatani persoalan ini tampaknya melalui lembaga pendidikan. Karena siswa yang datang untuk belajar menjadi desainer dapat dibentuk mental dan dasar pemikiran selama pembelajaran. Walaupun belum menjamin kelak mereka akan melakukan pekerjaan dengan mengindahkan pertimbangan yang ideal.

Setidaknya lembaga pendidikan desain dapat berperan serta untuk menekan kondisi ini melalui pembekalan pada siswa didiknya. Sarjana adalah tingkatan pendidikan tinggi yang harus menerapkan pertimbangan yang bijak dalam bidang kerjanya dengan mengantisipasi efek negatif.

\section{Referensi}

Bay Brix Nielsen, C. K. E., Daalhuizen, J., \& Cash, P. J. (2021). Defining the behavioural design spac. International Journal of Design, 15(1), 1-16. http://www.ijdesign.org/index.php/IJDesign/article/viewFile/3922/930

Burch, S. R. (2021). Perspectives on Racism: Reflections on Our Collective Moral Responsibility When Leveraging Arts and Culture for Health Promotion. Health Promotion Practice, 22(1_suppl), 12S-16S. https://doi.org/10.1177/1524839921996073

Dyah, W., Bambang, S., \& Arief, L. N. (2017). Analisis Sebaran Reklame Billboard Terhadap Lokasi dan Nilai Pajak Reklame Berbasis Sistem Informasi Geografis. Jurnal Geodesi Undip, 6, 100-109. https://ejournal3.undip.ac.id/index.php/geodesi/article/view/15226

Ferdy, R., \& Sari, W. P. (2020). Pengaruh Iklan Billboard Gojek Versi \#UninstallKhawatir Terhadap Brand Awareness. Prologia, 4(1), 106. https://doi.org/10.24912/pr.v4i1.6443

Herman Kurniawan, Adhar Arifuddin, M. M. (2017). DAMPAK MEDIA IKLAN (BILLBOARD ROKOK) TERHADAP PERILAKU MEROKOK SISWA DI SMK NEGERI 3 PALU. Healthy Tadulako Journal, 3(1), 71-84. https://jurnal.fk.untad.ac.id/index.php/htj/article/view/42

Homayoun, S., \& Henriksen, D. (2018). Creativity in business education: A review of creative self-belief theories and arts-based methods. Journal of Open Innovation: Technology, Market, and Complexity, 4(4). https://doi.org/10.3390/joitmc4040055

Kearns, A., \& Whitley, E. (2020). Are housing and neighbourhood empowerment beneficial for mental health and wellbeing? Evidence from disadvantaged communities experiencing regeneration. SSM - Population Health, 12(October 2019), 100645. https://doi.org/10.1016/j.ssmph.2020.100645

King, J. L. (2018). Summary of Twenty-First Century Great Conversations in Art, Neuroscience and Related Therapeutics. Frontiers in Psychology, 9(AUG), 1-7. 
https://doi.org/10.3389/fpsyg.2018.01428

Nilsson, A. W., \& Jahnke, M. (2018). Tactics for Norm-Creative Innovation. She Ji, 4(4), 375-391. https://doi.org/10.1016/j.sheji.2018.11.002

Ratu, A., Rai, N. G. M., \& Savitri, E. D. (2021). Excellent academic achievement: Do intellectual humility and emotional intelligence matter? Cakrawala Pendidikan, 40(2), 265-278. https://doi.org/10.21831/cp.v40i2.35588

Sakti, D. K., Studi, P., Komunikasi, I., Komunikasi, F., Informatika, D. A. N., \& Surakarta, U. M. (2020). Pengaruh Terpaan Iklan Media Luar Ruang Provider Xl. http://eprints.ums.ac.id/88305/1/Naskah Publikasi.pdf 